\title{
A Carne e o Mar: 0 Matadouro da Praia de Santa Luzia (1777-1853)
}

Lucas Erichsen ${ }^{1}$

\section{RESUMO}

Junto das fábricas, fazendas, laboratórios e zoológicos, os matadouros de animais para o consumo humano de carne foram alguns dos ambientes predominantes nas mediações das relações entre humanos e animais no século XIX e que podem ser analisados com o aparato teórico e epistemológico da história ambiental e da animal-human history. Isto posto, buscaremos tratar no presente artigo da história do matadouro da praia de Santa Luzia, o primeiro matadouro público do Rio de Janeiro, e compreendendo o mesmo enquanto espaço de constantes interações entre mundo biofísico, espécies animais destinadas ao consumo humano e da cidade com seus habitantes. Em 1853, durante as epidemias dos anos 1850, o matadouro foi desativado e depois transformado em Albergue, de modo que as práticas de matanças seriam deslocadas para outro lugar, trocando-se a praia e o mar pelos manguezais da cidade.

Palavras chave: História Ambiental; Matadouros; Rio de Janeiro

\footnotetext{
1 Doutor em História (Universidade Federal do Rio de Janeiro), Orcid: https://orcid.org/0000-0002-3225-000X, E-mail: lucaserichsen@outlook.com
} 


\section{INTRODUÇÃO}

Durante o século XIX, fábricas, fazendas, laboratórios ${ }^{2}$ e zoológicos $^{3}$ foram alguns dos ambientes onde relações entre animais e humanos ${ }^{4}$ eram mediadas $^{5}$, sendo estes lugares ambientes tecnológicos que transformaram os habitats e as ecologias dos animais e das relações humanos-animais. ${ }^{6}$

Os matadouros podem ser somados a tal afirmação e analisados com o aparato teórico e epistemológico da história ambiental e da animal-human history. De modo geral, podemos dizer que a primeira matriz disciplinar localiza os acontecimentos históricos não apartados do mundo biofísico e a segunda trata de apresentar os animais como agentes envolvidos em processos sociais. ${ }^{7}$ Não esquecendo da presença humana, ganha-se forma um tipo de história que ressalta a complexidade do mundo em suas mais diferentes interações.

O aparecimento dos matadouros públicos no século XIX permitiu controlar a sanidade da carne animal para que a mesma adentrasse o corpo das pessoas para que estas não fossem contaminadas e adoecessem, maior poder sobre os corpos dos animais que eram levados aos matadouros e sobre os corpos humanos que lá executavam as mais diversas atividades.

Devemos ressaltar que a historicidade dos matadouros no século XIX foi constantemente atravessada pela biopolítica, haja visto que naquele século, temos a emergência de um novo saber político e de novas disciplinas como estatística, demografia, epidemiologia e biologia. ${ }^{8}$ Nesse sentido, a Biopolítica compreenderia as formas de subjetivação que, ao atravessarem os sujeitos humanos, eram guiadas por

\footnotetext{
2 Joanna Dean. "Animal Matters: Bovine Smallpox Vaccine at the Connaught Laboratories and University Farm". In: Adcock, Tina. Landscapes of Science. (Toronto: Network in Canadian History and Environment, 2018).

3 Patrick Wirtz. "Zoo city: Bourgeois values and scientific culture in the industrial landscape.", Journal of Urban Design, 2:1, 61-82 (1997); Tracy Mcdonald, Daniel Vandersommers. "Zoo Studies: A New Humanities". (McGill-Queen University Press, 2019)

4 Para este artigo, não utilizaremos conceitos como: animais não humanos e animais humanos, mas somente animais e humanos para assim não confudir o leitor não habituado a tais distinções.

${ }^{5}$ Lorraine Daston; Gregg Mitman; "Introduction: How and Why of Thinking with Animals". Thinking with animals: new perspectives on anthropomorphism, (New York: Columbia Univ. Press, 2005).

6 Idem.

7 Hilda Kean; Philip Howell. "The Routledge Companion to Animal-Human History". (First published 2019. Routledge);

8 Thomas Lemke. Prospect: "An Analytics of Biopolitics In: Biopolitik zur Einfuhrung./Biopolitics: An Advanced Introduction" ( New York University Press. 2011)
} 
autoridades científicas, médicas, morais, religiosas e outras autoridades embasadas em arranjos socialmente aceitos sobre os corpos. ${ }^{9}$ Um aprofundamento na compreensão do que seria a biopolítica requerendo um conhecimento mais amplo do que é a vida, o viver e os seres vivos. ${ }^{10}$

Ainda no século XIX, os matadouros ganham forma enquanto instituição ordenada pelo Estado ${ }^{11}$ onde a matança de animais para o consumo humano deveria ser concentrada, ao contrário das matanças de quintais, em mercados de rua ou celeiros. $^{12}$

Locais de constante interação com o mundo biofísico, os matadouros sempre necessitaram de abundante fornecimento de água e de espaço para alocar os animais antes de serem mortos e transformados em carne, materialidade animal e fonte de energia que era essencial ao metabolismo urbano, sendo este um processo de alocar energia para diversas atividades da população no ambiente urbano. ${ }^{13}$

Materialidade animal comestível que só chegava aos açougues e pratos de parte da população que habitava o ambiente da cidade do Rio de Janeiro após passar por uma interagência ${ }^{14}$ de humanos e animais que ao agir e fazer agir $^{15}$ por meio do processo de desanima(liza)ção ${ }^{16}$ em uma da estrutura sociocultural escravagista. ${ }^{17}$

\footnotetext{
9 Lemke, Biopolics

10 Lemke, Biopolics

11 Amy J. Fitzgerald. "A Social History of the Slaughterhouse: From Inception to Contemporary Implications". Human Ecology Review, Vol. 17, No. 1, 2010

12 Lucas. V. E. da Rocha, "Passagens e novas fronteiras dos abates: o Matadouro Municipal de Ponta Grossa e a historicidade dos espaços de matança animal centralizada”.( Dissertação de mestrado, Universidade Estadual de Ponta Grossa, Paraná, 2015; Chris Otter. "The vital city: public analysis, dairies and slaughterhouses in nineteenth-century Britain. Cultural geographies 2006.; Paula Young Lee. Meat, Modernity, and the Rise of the Slaughterhouse". (University Press of New England, 2008).

13 Chris Otter. "Planet of Meat: A Biological History". Material Powers: Challenging (the) Humanities (Canberra: The Australian Academy of the Humanities, 2013); Erik Swyngedouw. "The City as a Hybrid -- On Nature, Society and Cyborg Urbanisation", Capitalism, Nature, Socialism, (Vol. 7(1), Issue 25 March. 1996); Samuel Niza et. al. "Lisbon's womb: an approach to the city metabolism in the turn to the twentieth century". Regional Environmental Change (16(6):1-13 2016); Geoffrey West. "Scale: The Universal Laws of Growth, Innovation, Sustainability, and the Pace of Life in Organisms, Cities, Economies, and Companies." (Penguin: 2017).

14 Vinciane Despret. "From secret agents to interagency". History and Theory, (52: 29-44. 2013)

${ }^{15}$ Hilda Kean; Philip Howell. "Writing in animal in history" Companion to Animal-Human History, 4-19; Philip Howell. "Animals, agency, and history" Companion to Animal-Human History,523-533; Radhika Govindrajan. "Animal Intimacies: Interspecies Relatedness in India's Central Himalayas". (1 edition. Chicago: University of Chicago Press, 2018); Sara McFarland; Ryan Hediger. "Animals and Agency: An Interdisciplinary Exploration". (Leiden, The Netherlands: Brill, 2009); Ursula K. Heise; Jon Christensen; Michelle Niemann. "The Routledge companion to the environmental humanities". (New York, NY: Routledge, 2016).

${ }^{16}$ Quando se é retirado de um animal o anima (aquilo que dá vida) e depois a animalidade (aquilo que identifica um animal como um animal). para então o animal se tornar carne para o consumo humano. Juliana Vergueiro Dias. "O rigor da morte: a construção simbólica do "animal de açougue" na produção industrial brasileira". 2009. Dissertação de mestrado (Universidade Estadual de Campinas, 2009); Otter. The vital city, 2006. Lucas. V. E. da Rocha, "Passagens e novas fronteiras dos abates" 2015;, Noëlie Vialles. Animal to edible. (Cambridge Univ. Press [u.a.] 1994); Roel Sterckx, "Animal to Edible - The Ritualization of Animals in Early
} 
Com estes aparatos teórico-metodologicos de diferentes matrizes disciplinares, abordaremos as fontes selecionadas para compreender como que durante o despejo de resíduos das matanças nas águas da Baía da Guanabara, na mão de obra utilizada, nos vislumbres sobre os saberes e técnicas que envolviam as práticas de matança animal e dos usos do matadouro conforme as pecepções acerca do ambiente urbano se transformaram ao longo da primeira metade do século XIX, que o matadouro de Santa Luzia era um espaço de constantes interações entre: o mundo biofísico, humanos e espécies animais destinadas ao consumo humano e da cidade com seus habitantes.

\section{A Corte, o OURo e o Matadouro}

Sabe-se que por volta do ano de 1777 , boa parte do gado morto ${ }^{18}$ para o consumo dos moradores do que hoje é o centro urbano do Rio de Janeiro, era feita nos arredores da região central ${ }^{19}$. Dificilmente alguém imaginaria que um dia, estes locais pudessem ganhar forma como um espaço de matanças concentradas. Assim, com o início do ciclo aurífero em metade do século XVIII e a construção do chamado 'caminho novo' que ligava o Estado de Minas Gerais e Rio de Janeiro, a cidade do Rio de Janeiro foi elevada a condição de capital da Colônia e sede do Vice Reino.

Nessa direção, uma assertiva de Lewis Mumford, a de que todos os caminhos sempre levam às capitais, ${ }^{20}$ ganha forma. Sendo as cidades recipientes e aglutinadoras de fluxos, uma capital é o local de todos os caminhos e, no caso do Rio de Janeiro, os caminhos estariam relacionados aos novos fluxos de passagem de ouro e diamantes levando a emergência de condições inesperadas que caracterizam a complexidade urbana. Ademais, é possível deduzir que isso levou a um sensível aumento populacional (ainda não comparável com aquele que iria ocorrer em 1808 com a

China" In: Roel Sterckx; Martina Siebert; Dagmar Schäfer. (Org). Animals through Chinese History: earliest Times to 1911.( New York, NY: Cambridge University Press, 2019).

${ }_{17}$ Ao contrário de uma historiografia sobre matadouros e produção de carne majoritariamente oriunda do hemisfério norte, o caso brasileiro se mostra mais complexo e sensível pelo inseparável elemento da mão de obra escrava.

18 Evitamos o uso da palavra abatido pelo fato de que os usos das palavras abater, abatido ou abatedouro aparecem (ao menos no caso brasileiro) somente no início do século XX.

${ }^{19}$ Georgia Tavares. "A atuação dos marchantes no Rio de Janeiro colonial. Estratégias de mercado e redes de sociabilidade no comércio de abastecimento de carne verde 1763-1808. (Dissertação de mestrado 2012): 60.

20 Lewis Munford. A cultura das cidades. Tradução Neil R. da Silva. (Belo Horizonte: Itatiaia, 1982): .237 
chegada da corte portuguesa) e que constituiu uma alteração no metabolismo do Rio de Janeiro e em seu consumo de carne.

As práticas de matança tornaram-se insuficientes frente ao incremento populacional, do consumo de carne e das necessidades energéticas depois da metade do século XVIII. Talvez seja por isso que em 1777 tenha sido inaugurado o primeiro matadouro público do Rio de Janeiro, edifício que figurou entre uma das principais realizações daquela década como podemos perceber no relatório de 19 de junho de 1779 sobre as a gestão do $2^{\circ}$ Marquês do Lavradio, Luís de Almeida Portugal Soares de Alarcão d'Eça e Melo Silva Mascarenhas, título concedido a maior autoridade política da Colonia:

[...]fazerem-se mais duas fontes públicas, muitas pontes, consertarem os caminhos, juntar e entalharem-se infinitos pântanos, que haviam na cidade, origem de infinitas moléstias. Fizeram-se currais e matadouros públicos; está arrematada a obra do açougue, a casa da Câmara. Abriram-se novas ruas para se fazer melhor comunicação da cidade, e daqui por diante [.....$^{21}$

Um matadouro público centralizaria não só as matanças, mas também o controle governamental no sistema de distribuição da carne, alimento que muitas vezes era chamado de 'gênero de primeira necessidade'. Tal controle e centralização seriam as primeiras tentativas de se adaptar a um progressivo crescimento da cidade que perduraria ainda nas próximas décadas.

Em vista de estabelecer o novo local de matança, utilizou-se de uma casa já em construção na antiga Praia de Santa Luzia, entre a igreja de mesmo nome e o Campo da Ajuda. ${ }^{22}$ Ainda, a necessidade de limpar os espaços de matança e despejar os resíduos das mesmas, fez com que na maioria das vezes, a construção de matadouros sempre fosse efetivada em contato com corpos de água, quer seja um rio, um lago ou o mar, como foi no caso do Rio de Janeiro.

Para o caso do Rio de Janeiro no final do século XVIII e início do século XIX, a praia era a margem e o ponto limite da cidade. Pelas águas do mar chegavam e partiam continuamente os mais diversos agentes humanos, minerais e animais. Pelas águas do mar é que os resíduos produzidos durante o processo metabólico da cidade,

\footnotetext{
21 Jaime Bechimol. Pereira Passos, um Haussmann tropical: a renovação urbana da cidade do Rio de Janeiro no início do século XX. (Cia das Letras, São Paulo, 1990). 21-22

22 Geórgia da Costa Tavares. A atuação dos marchantes no Rio de Janeiro colonial.61
} 
deveriam encontrar seu destino. Por conta disso, o primeiro matadouro público do Rio de Janeiro foi construído à beira-mar. ${ }^{23}$ Sobre as areais da praia de Santa Luzia, na baía da Guanabara, interagiam a cidade, a carne e o mar.

Durante o período de seu funcionamento, o matadouro de Santa Luzia foi motivo de constantes problemas na Câmara Municipal, principalmente no que dizia respeito às questões do abastecimento de carne na cidade e sobre o chamado monopólio de carne verde ${ }^{24}$, problema agravado com a chegada da Família Real e de toda a sua corte em $1808 .^{25}$ Ou seja, partir do momento em que o Rio de Janeiro deixa de ser capital do Vice-Reino e se torna capital do então Império Português, o matadouro de Santa Luzia jamais voltaria a suprir a demanda de carne necessária para o consumo diário dos habitantes da cidade, enfrentando problemas de fornecimento de carne verde ${ }^{26}$ que só se agravariam com o passar dos anos.

Até pouco depois da chegada da Família Real, o Alcaide-mor era o responsável pela distribuição da carne, fiscalização das matanças e do açougue municipal do Rio de Janeiro que ficava no mesmo prédio da Câmara Municipal. ${ }^{27}$ Por mais que as práticas de matança animal para o consumo humano naquele Rio de Janeiro de início do século XIX estivessem sob a égide das Ordenações Filipinas, tais ordenamentos referem-se muito pouco aos matadouros e versam somente da necessidade de cortar carne nos açougues e, por vezes, fazem referências genéricas aos chamados carniceiros. Tal ofício parece ser considerado um dos mais relevantes ao ponto do primeiro livro das ordenações Filipinas, em seu título XVIII sobre o Almotacé-mor, os carniceiros serem reconhecidos como necessários para manter a Corte.

\footnotetext{
23 Pedro Henrique Pereira Campos. Nos Caminhos da Acumulação: negócios e poder no abastecimento de carnes verdes para a cidade do Rio de Janeiro, 1808-35. Dissertação de mestrado (Universidade Federal Fluminense Niterói, 2007); Thomas Ewbank. Life in Brazil; or A Journal of a visit to the Land of the cocoa and the palm. (Harper \& Brothers Publisher. New York. 1856); John Luccock. Notes on Rio de Janeiro, and the Southern parts of Brazil; taken during a residence of ten years in that country, from 1808 to 1818. (London, 1820).

24 Pedro Henrique Pereira Campos, Nos caminhos, 2007; Georgia da Costa Tavares, A atuação dos marchantes , 2012.

25 Pedro Henrique Pereira Campos., Nos caminhos, 2007.

${ }^{26}$ Embora os agentes da indústria frigoríica atual por vezes utilize 'carne verde' como sinônimo de sustentável e ecologicamente correta, a carne verde do século XIX era a carne recém cortada (fresca, em processo de esfriamento e sem nenhum tratamento para conservação à maneira do charque, por exemplo) de uma carcaça animal.

27 CARTA do ouvidor-geral do Rio de Janeiro, Agostinho Pacheco Teles, ao rei [D. João V], informando a inexistência de uma provisão, que determine o aumento do salário do escrivão da Câmara daquela cidade pelo registro das cabeças de gado entregues no açougue municipal. Disponível:<http://acervo.redememoria.bn.br/redeMemoria/handle/123456789/203041> Acesso: 26/05/2017
} 
Este tipo de trabalho em um primeiro momento se mostra próximo daquele das guildas de ofícios, "associação de mestres a trabalharem seus produtos, agrupados a fim de regularizar a produção e estabelecer padrões de grande habilidade"28 e diferente das guildas de mercadores, que buscavam organizar e ter controle da vida econômica de uma cidade. ${ }^{29}$ Porém, e particularmente no caso do Rio de Janeiro, a utilização de mão de obra escrava dava forma a um tipo de trabalho muito diferente ao das guildas europeias.

O código não menciona pessoas que matavam animais para o consumo humano em suas próprias residências, curtumes, nos locais de venda ${ }^{30}$, celeiros ou currais que, para nossas percepções atuais, classificaríamos de imundos, com técnicas e instalações precárias. ${ }^{31}$ Seja como for, é possível inferir que a mencionada importância dos carniceiros se devia ao fato de que eles participavam de todas as etapas da desanima(liza)ção, ou seja, eram responsáveis pela matança, trinchamento e posterior venda dos pedaços de carne. ${ }^{32}$ Uma das principais fontes de energia da população no ambiente urbano.

Quanto à regulação de tal ofício, por volta de 1830 com a fundação da nova Câmara $^{33}$ e após a primeira constituição brasileira, passamos a ter legislação um pouco mais específica sobre matanças quando são publicadas as primeiras posturas sobre a necessidade de se matar bois unicamente no matadouro de Santa Luzia sob o título de "Economia e asseio dos currais, matadouros e açougues públicos ou talhos"34, que a Câmara do Rio de Janeiro passaria a instituir novos dispositivos de controle em relação aos matadouros, dos carniceiros, dos corpos dos bois e da carne proveniente destes ao consumo humano.

Não somente, deixava-se de usar o termo 'cortar carne' para se referir a totalidade do processo antes desempenhando integralmente pelos carniceiros,

\footnotetext{
${ }^{28}$ Munford. A cultura das cidades. 1982. 296

29 Idem.

30 Otter. The vital city. 2006; lan Maclachlan. "A bloody offal nuisance: the persistence of private slaughterhouses in nineteenthcentury London". Urban History (34(02):227 - 254 2007); Lucas. V. E. Da Rocha. "Passagens e novas fronteiras dos abates”, 2015.

31 Vale notar que não existe precariedade técnica ou tecnológica. Estas sempre servem aos seus propósitos quando são utilizadas ou desenvolvidas. Veremos isso de maneira melhor elaborada em outro momento deste trabalho.

32 Antonio Pádua Bosi. "Dos Açougues aos Frigoríficos Uma História Social do Trabalho na Produção de Carne, 1750 a $1950 "$. Revista de História Regional. (19(1): 83-103, 2014); lan Maclachlan. A bloody offal nuisance. 2007,; Otter. The vital city. 2006; Lucas. V. E. da Rocha. Ibid, 2015.

33 Pedro Henrique Campos. Caminhos da Aucmulação. 2007

${ }^{34}$ Código de Posturas. Título IV - Economia e aceio dos curraes e matadouros, açougues publicos ou talhos p.4
} 
passando-se a utilizar o termo 'matar' e 'esquartejar' no que dizia respeito, respectivamente, ao ato de matar reses e cortar a carne das mesmas. Ao que parece, até a publicação das posturas de 1830, não existiam referências ao ato de matar bois, porcos e carneiros e haviam somente leis sobre a obrigação de se cortar e vender carne unicamente em açougues. Por sua vez, se fossem açougues das vilas ou aldeamentos, deveriam seguir estritamente as leis do código Filipino e, à maneira dos açougues das universidades e conventos, deveriam ser reconhecidos como apartados. Quando os açougues fossem públicos, seriam classificados em dois tipos: o açougue grande (onde existiam diversos talhos pequenos, um próximo do outro) e o açougue pequeno $^{35}$.

De todo modo, quer seja antes ou depois das resoluções de 1830, sempre foi necessário destinar a carne o mais imediatamente possível aos postos de venda, trabalho de transporte que deveria ser realizado o mais rapidamente possível. Assim, escravos deveriam carregar os grandes, ensanguentados e quentes pedaços de carne até os locais de venda como podemos perceber no artigo $7^{\circ}$ de "Economia e asseio dos currais, matadouros e açougues públicos ou talhos":

$\S 7 .^{\circ}$ As carnes serão conduzidas para os talhos em carroças ou cestos, envoltas em panos, ficando absolutamente proibida a condução á cabeça de pretos, sem ser em cestos, sob pena de $4 \$ 000 .^{36}$

Outra maneira de inferir os modos de transportar carne naquele Rio de Janeiro entre finais do XVIII e primeira metade do XIX diz respeito às representações que Jean-Baptiste Debret publicou em seu“Viagem pitoresca e histórica ao Brasil". Em uma das imagens do livro, encontramos uma venda de carne de porco ${ }^{37}$ onde é claramente visível a presença de dois escravos carregando sobre suas cabeças, porcos inteiros que depois seriam esquartejados no pequeno açougue que aparece na Figura 01.

Elementos singulares à história dos matadouros no contexto brasileiro são visíveis: a presença de uma criança e mulher escravas no interior da pequena venda

\footnotetext{
35 Geórgia da Costa Tavares. A atuação dos marchantes no Rio de Janeiro colonial. 2012.

36 Código de Posturas. "Título IV - Economia e aceio dos curraes e matadouros, açougues publicos ou talhos" In: CODIGO DE POSTURAS Leis, decretos, editais e resoluções da Intendencia municipal do Distrito Federal. Compilação feita por ordem da Prefeitura, pela repartição do Archivo Geral. (Rio de Janeiro - Papelaria e Typografia Mont'Alverne. 1894).6

37 Figura 2 - Boutique d'un marchand de viande de porc. In: DEBRET, Jean-Baptiste.Voyage pittoresque et historique au Brésil. Tome deuxième. P.142-143, passim
} 
provavelmente comprando carne para outrem; a cabeça de porco pendurada na parte esquerda da porta provavelmente para que ela estivesse sempre arejada e para que se adiasse o máximo possível a putrefação; a balança como ferramenta para aferir pesos e então calcular preços; toda a estrutura de madeira onde a carne é exposta e cortada; aquele que atende ser um escravo e possivelmente propriedade do homem à direita do estabelecimento que retira concentradamente o couro de um porco. ${ }^{38}$

Figura 01. Boutique d'un marchand de viande de porc: $O$ açougue era de carne de porco, os quais não eram mortos no matadouro público, mas sim em qualquer outro lugar da cidade.

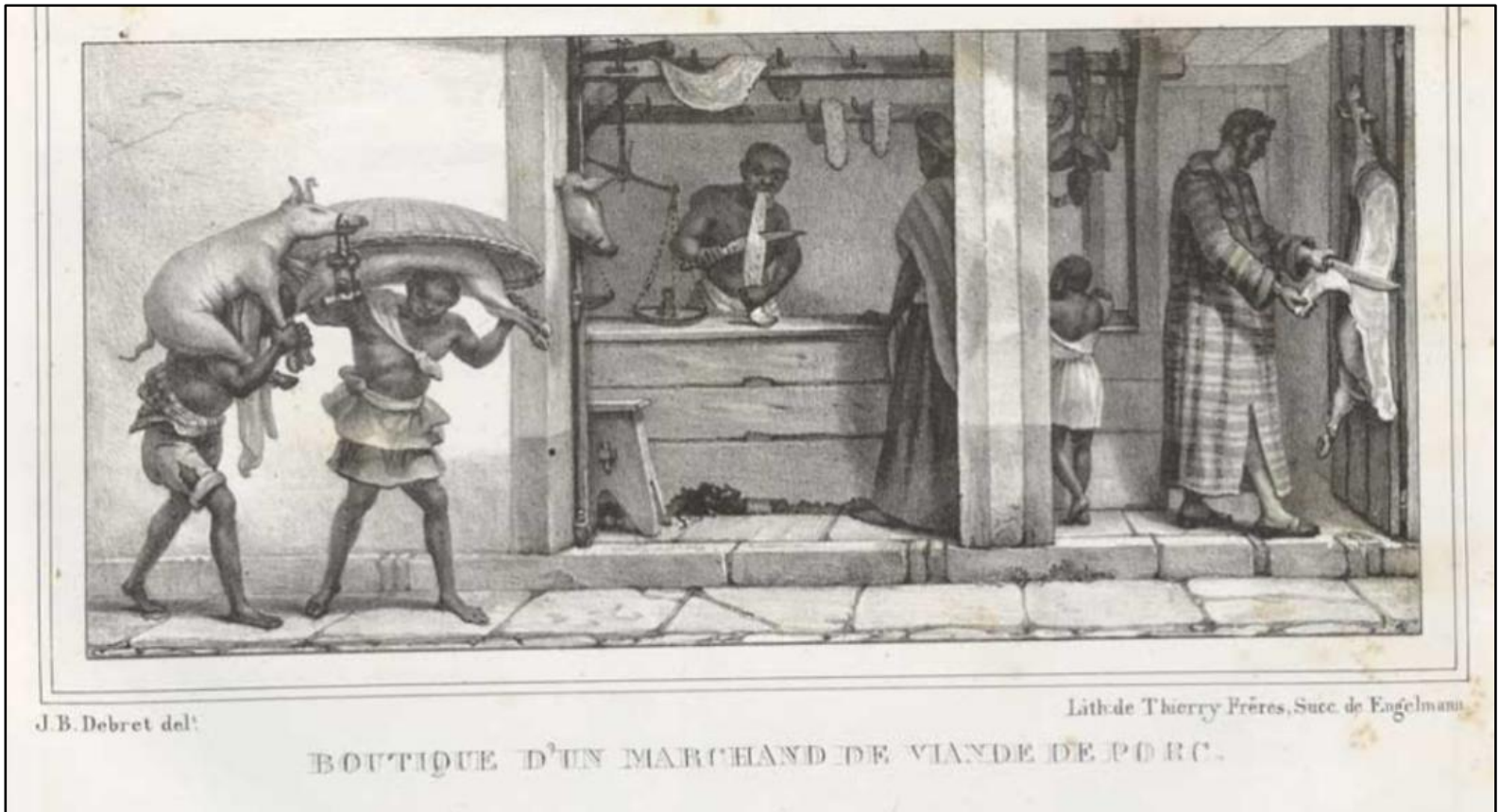

Fuente: J.B. Debret de ${ }^{39}$

\section{O Matadouro, a CARne E O MAR}

Em 1808, em "Reflexões sobre alguns dos meios propostos por mais conducentes para melhorar o clima da cidade do Rio" ${ }^{40}$, são abordados os mais diversos aspectos da capital do Império, da salubridade da cidade e das reformas necessárias.

\footnotetext{
38 Deve-se ressaltar o fato de que toda a imagem não contém única referência ao sangue. Este elemento diz respeito a estética empregada por Debret (pois nem as imagens onde aparecem escravos sendo castigos contém sinal de sangue) do que as condições reais daqueles estabelecimentos. Apagamento que também ocorre em fotografias utilizadas na divulgação de laboratórios produtores de vacinas após o inicio do século XX buscaram apagar qualquer relação com sangue e violência. Sobre isso ver: Joanna Dean. Animal Matters. 2018.

39 Figura 2 - Boutique d'un marchand de viande de porc. In: DEBRET, Jean-Baptiste.Voyage pittoresque et historique au Brésil. Tome deuxième. P.142-143, passim

40 Manoel Vieira da Silva. Reflexões sobre alguns dos meios propostos por mais conducentes para melhorar o clima da cidade do Rio. (Rio de Janeiro, RJ: Impr. Régia, 1808)..
} 
Nesta publicação de Manoel Vieira da Silva, a qual compunha a primeira leva de publicações da Imprensa Régia, ${ }^{41}$ também encontramos um teor textual que é composto por uma mistura de saber e autoridade técnica com subserviência à monarquia.

Assim, neste texto cujas reflexões eram pertinentes para aquele primeiro ano de instalação da família real, o matadouro, sua localização e o consumo de carne aparecem como elementos cruciais:

Tendo falado dos alimentos do Reino Animal, que entram na Cidade privados de vida, segue-se fazer algumas reflexões sobre os que chegam dotados dela, quais são os gados para o consumo da cidade.

Entram as grandes manadas de gado, que devem durar para toda a semana, cansadas da grande jornada, em que se tem privado de alimentos, são introduzidos no curral, onde igualmente estão alguns dias sem alimento e água, e aí, ou o transtorno das suas funções vitais lhe põe termo à vida, ou chegam ao matadouro, conservando apenas as aparências.

É uma verdade demonstrada em Medicina, que os sucos gástricos do homem tem grande ação sobre as carnes, e que esta segue a razão direta da perfeição das carnes, isto é, que elas se digerem tanto melhor, quanto era mais perfeito o estado de vitalidade daqueles animais, que são empregados no nosso alimento.

\section{$[\cdots]$}

Donde se deduz a necessidade de fazer entrar no Curral o gado necessário só para um dia, havendo na vizinhança da cidade lugar próprio para a demora dele e onde possa recuperar parte das forças perdidas na jornada: deste modo poderemos gozar de carnes mais saborosas, e de melhor nutrição, ainda que o seu preço seja mais subido; porque os defeitos públicos não podem emendarse sem o concurso do mesmo publico; e é só da concorrência das forças particulares, que resulta a força geral do Estado. ${ }^{42}$

Ao mesmo tempo em que o médico da Real Câmara ressalta que a origem do gado destinado ao consumo não era das proximidades do Rio de Janeiro, percebe-se algo de uma moral utilitarista muito diferente daquela que surgiria em finais do XIX. Assim, quando Manoel Vieira busca construir seu argumento na diferenciação dos tipos de alimentos de origem animal que abasteciam a cidade reconhece os bois como seres dotados de vida, mas também os compreende como estoque vivo. Desse modo, ao afirmar que os bois nem sempre chegariam sadios ao matadouro onde somente manteriam suas aparências animais, e tendo em mente as condições de publicação do texto, percebe-se nas entrelinhas que os animais cujo anima não partilhavam mais da

\footnotetext{
41 Teresa-Cristina Duarte Simões. "A saúde pública no Rio de Dom João". Caravelle. Cahiers du monde hispanique et luso-brésilien, (Presses Universitaires du Mirail, 2008). .285-287 ; Alisson Eugenio. Saber médico, cultura e saúde pública no brasil do século XIX. sÆEculum - Revista de história. (João Pessoa, jan./ jun. 2010).

42 Manoel Vieira da Silva. Reflexões. 1808..
} 
vitalidade, ameaçariam a boa alimentação humana e o consumo da carne. Estas eram as únicas preocupações existentes para com os bois, um postulado que anos depois, ainda no século XIX, seria apontado por outros personagens, tal como o químico alemão Justus Von Liebig ${ }^{43}$ que "argumentou que a carne era essencial para reparar tecidos danificados: ela fortalecia corpos, cidade e nações". ${ }^{4}$

Dando continuidade aos seus argumentos, Manoel Vieira da Silva aponta que urina, fezes e diferentes partes animais se opõem a salubridade da cidade e passa a questão de porquê o matadouro público não seria um problema por conta de tais aspectos.

A busca por tentar transparecer que o matadouro não era o maior dos problemas para a cidade, e talvez isso tivesse relação em demonstrar aos poderes imperiais que estes não deveriam se preocupar pois os gestores e o povo do Rio de Janeiro estariam alinhados no que dizia respeito ao suprimento daquele gênero de primeira necessidade, em como o local de matanças estava à altura do novo soberano recém chegado da Europa, ao Império que era vislumbrado e como que ao encontrar problemas, os súditos não somente sabiam dos mesmos como tinham vontade de resolve-los:

Quem entra no matadouro é obrigado a louvar a escolha do local, e a maneira porque ele está construído, ali se encontra uma espaçosa casa, cujas paredes são formadas por grades de madeira, que facilitam a livre corrente do ar, tão necessária para os empregados naquele trabalho, cujas vidas merecem a contemplação do Estado. Ela é toda lajeada, munida dos diferentes canos, que devem dar saída ao sangue, ao lado esquerdo há um poço, que por meio de uma bomba, e canos próprios fornece toda agua necessária à lavagem da casa depois de concluído o corte, a sua situação na praia não consente a demora de semelhantes águas e do sangue, de que poderiam resultar danos, porque se misturam logo com as do mar; em todo o resto do arranjo, o próprio a semelhante casa, ela deixa ver habilidade da mão, que a construiu. O nosso Soberano não poderia conseguir atualmente um edifício semelhante, sem que a despesa não montasse acima de sessenta mil cruzados.

Acontece o contrário a respeito do curral, onde os excrementos de animais parecem que tem sido demorados, depois que ali existe o matadouro e por isso inquina toda aquela porção de ruas, que lhe ficam próximas, com um péssimo cheiro e acaba de extinguir a vida aqueles animais demorados na forma que já se disse.

Conclui-se de tudo, que a falta de asseio no matadouro, para o que ele tem as comodidades, a mesma falta ao curral pela sua má construção, e o lançar à

43 O nome de Liebieg também foi utilizado por industrias frigorificas da América Latina.

44 Liebig, for example, argued that meat was essential to repair damaged tissue: it strengthened bodies, cities and nations. Otter.. The vital city. 2006. 526. 
praia as cabeças, e diferentes partes dos animais, sem que fiquem enterradas, são as únicas causas que podem ser acusadas, como opostas a salubridade do $\operatorname{ar}^{45}$

Ao mencionar que cabeças de animais e outras partes dos mesmos eram arremessadas à praia, ressalta-se o papel do mar como protótipo do esgoto, como espaço de lavar e levar embora os restos do matadouro. Para o médico Real da Câmara, a proximidade com o mar era um verdadeiro triunfo da engenharia e da higiene, construções humanas e mundo biofísico funcionavam em mútua cooperação e invejável harmonia que talvez nem as cidades europeias, habituais aos membros recém chegada corte possuíssem.

A água que era captada de um poço limpava os restos animais e lavava o sangue que depois escorria em direção ao mar. Se tratando de um matadouro que ficava à beira da praia, é possível imaginar que durante a noite e com a subida da maré, o local era novamente lavado pelas águas da Baía de Guanabara. Não que isso significasse que o matadouro e a praia em seu arredor fossem cotidianamente purgados dos resíduos de matanças, das cabeças de gado e de diferentes partes dos animais que, como bem salientou Manoel Vieira da Silva, eram atiradas ao mar.

Isto pode ser afirmado pois cada um desses resíduos evidentemente possuía densidade menor que a do mar, cujo fluxo nem sempre conseguiria levar embora. algo que ocorria em todas as cidades do século XIX que tinham matadouros em constante interação com o mar, tal como Long Island, New Jersey ${ }^{46}$ e de São Francisco que, nos anos 1870, teria matadouros literalmente sobre as águas da baía da cidade, de modo que os resíduos das matanças imediatamente caíssem "na maré abaixo e fossem lavados duas vezes por dia pelo inexorável fluxo e refluxo de água salgada" ${ }^{47}$.

A necessidade de assear os matadouros, descartar e despejar os resíduos das matanças fez com que, na maioria das vezes, a construção de matadouros sempre fosse efetivada em contato com corpos de água, quer seja um rio, um lago ou o mar. Porém, no caso do Rio de Janeiro, parte dos resíduos das matanças encontrados nas

\footnotetext{
45 Manoel Vieira da Silva. Reflexões. 1808. 24-25

46 Catherine Mcneur. Taming Manhattan: environmental battles in the antebellum city. (Harvard University Press. London, England. 2014).

47 Andrew Robichaud. "Trail of Blood The Movement of San Francisco's Butchertown and the Spatial Transformation of Meat Production, 1849-1901". Stanford University Spatial History Lab (2010); Idem. "Animal City: The Domestication of Urban America". ) Harvard University Press, 2019).
} 
águas da praia de Santa Luzia, em frente ao matadouro, eram retirados do mar e voltavam ao ambiente urbano por conta dos escravos que após a finalização das matanças, estavam "presentes para apanhar e lavar as tripas para usá-las como enchimento de linguiça ou para finalidades de natureza doméstica ou medicinal" ${ }^{48}$ Relação dos escravos com o metabolismo urbano, seus excedentes e com o mar, quando o mesmo ainda era compreendido enquanto local de despejo de resíduos e que também ocorria quando "os esgotos da cidade do Rio de Janeiro eram despejados nas valas ou praias por meio de barris transportados por escravos, os soturnos "tigres", estes, que andavam pelas ruas com sua carga repugnante, tarde da noite". 49

Nessa direção, é importante ressaltar que para Manoel Vieira da Silva, o matadouro de Santa Luzia não precisava de melhorias, ao passo que o verdadeiro problema seria o curral repleto de fezes, moscas, odores e os prováveis corpos de bois que lá ficavam após algumas reses expirarem devido a algo igualmente indicado por John Luccock e Thomas Ewbank: as longas jornadas até a Capital do Império. Assim, Manoel Vieira da Silva destaca que o curral necessitaria de obras e deveria ser inteiramente repensado:

[...] Que o Curral deve rebaixar-se, e calçar-se, ou lajear-se, deixando canais para a pronta saída das urinas; bem como igualmente é necessário fazer um Cano principiado desde o nível do Curral, e continuado até o mar, tendo dois palmos de largura e três ou quatro de altura, por onde entre a agua da maré no curral e o lave, quando se julgar necessário, e para que a maré não entre no curral, quando não for necessária, deve ter o dito cano uma adufa de pão, que posta, embarace a entrada da água da maré no curral

Em quanto ao local, já fica dito; que ele é o melhor, e no caso de aparecer outro igual, ele ficaria sujeito aos mesmos inconvenientes [...] quando o matadouro estivesse légua e meia, ou duas em distancia da Cidade, de que resultavam maiores prejuízos em razão da condução das carnes, e da corrupção, de que elas são suscetíveis, durante o seu transporte, $[. . .]^{50}$

A qualidade da carne era pensada no sentido de que bois cansados e magros não resultavam em boa carne verde e muito menos em bons pesos para serem vendidos nos talhos da cidade da mesma forma que a localização do matadouro era a melhor possível, pois assim evitava-se de transportar a carne por longas distâncias,

\footnotetext{
48 "Into that water the offal also is thrown, where it floats about, unless a sufficient number of black people, of the lowest order, be present to seize and wash the entrails as cases for polonies, or for other purposes of a domestic or medicinal nature". John Luccock. Notes on Rio de Janeiro. 1820. 43.

49 Jaime Benchimol. Pereira Passos, um Haussmann tropical. 1990. 72

50 Manoel Vieira da Silva. Reflexões 1808. 25-26
} 
algo essencial em uma cidade com o clima do Rio de Janeiro e em um período em que os sistemas de refrigeração estavam longe de serem inventados.

Ademais, enquanto Manoel Vieira da Silva louvava a estrutura das paredes que auxiliariam na circulação de ar por ser necessária aos trabalhadores, deve-se ressaltar que o então médico Real da Câmara não menciona quem seriam estes trabalhadores, algo que Thomas Ewbank tratou de evidenciar:

\begin{abstract}
"Dois negros altos e atléticos, com nada além de calções de lona grossa, manchados de sangue, seguravam machados na vertical, do comprimento de seus braços, acima de suas cabeças, e continuavam andando devagar. Seis outros homens, com estacas montadas com espetos, lideravam os confusos animais. Sempre que algum se mantinha firme por um momento, ou caminhava devagar, um machado era enterrado em seu pescoço atrás dos chifres e, num instante, caía. Assim prosseguiram até que todos caíssem, quando um negro, com um pedaço de trapo ao redor da cintura, sangrou-os mergulhando uma faca em suas gargantas.. ${ }^{\$ 1}$
\end{abstract}

A descrição de Ewbank permite novamente salientar a particularidade da história dos matadouros do Rio de Janeiro, no que se refere ao tipo de mão de obra ao mesmo tempo em que temos informações sobre as práticas, ferramentas e, por consequência, técnicas empregadas para a matança dos animais.

A imagem que se tinha do matadouro de Santa Luzia era a de uma casa de matança com paredes vazadas que permitiam enxergar as atividades internas, onde "um administrador junto a uma mesa com todo o interior do matadouro à sua frente, separado somente por uma baixa partição, não maior que um balcão" ${ }^{\text {"52 }}$ acompanhava escravos portando lanças, machados e facas desferirem golpes nos corpos das reses que, ao sangrarem, cobriam de sangue tanto os corpos seminus daqueles mesmos escravos quanto o chão do matadouro, o qual também era repleto de corpos de bois em todas as posições possíveis. Processo de desanima(liza)ção que por vezes sofria interrupções quando algum boi confuso ou que resistia a imobilização pré matança, elementos que somados aos relatos de bois que ao longo dos anos continuavam a escapar dos matadouros ${ }^{53}$ e da necessidade de legislar para que os bois fossem

51 Thomas Ewbank. Life in Brazil. 1856. P. 64

52 lbid

53 Gazeta de Notícias - 28/01/1876; Jornal do commercio, 26/07/1877; 
conduzidos somente durante a madrugada, ${ }^{54}$ indica capacidade de agência dos animais em agenciamentos conjuntos as ações dos trablhadores do local ${ }^{55}$.

Processos que ocorriam à beira-mar, onde constantemente eram despejados os resíduos animais, cujas águas durante a subida noturna da maré quebravam em ondas que lavavam o ambiente interno do matadouro levando aquilo que restou das matanças durante o dia e tornando as águas naquelas proximidades descoloridas e manchadas. Águas que tinham restos de animais boiando ao mesmo tempo em que escravos entravam no mar para pegar restos de proteína animal enquanto que os já mencionados "tigres" despejavam - naquelas mesmas águas da Baía de Guanabara, os resíduos metabólicos dos habitantes da cidade.

Assim, até o início dos anos 1840, o matadouro de Santa Luzia ganhava pequenos reparos ${ }^{56}$ e tanto seu ambiente interno quanto a localização do matadouro não eram considerados problemas e as principais preocupações diziam respeito somente às condições pré-matança e pós-matança.

\section{Do MAR Ao MANGUE}

Em 1843, o matadouro de Santa Luzia começa então a ser considerado um "imundo telheiro, cercado de imundíssimas barracas, cujas evaporações produzem enfermidades endêmicas nas suas circunvizinhanças" ${ }^{57}$ quando é elencado naquele que é considerado o primeiro plano urbanístico da cidade do Rio de Janeiro, ${ }^{58} \mathrm{o}$ relatório de Henrique de Beaurepaire Rohan, então Diretor das Obras Municipais. Mudança de percepção acerca do matadouro imersa em um contexto no qual a capital do novo Império do Brasil apresentava aumento populacional, incremento da densidade urbana e problemas com as primeiras epidemias. Ou seja, o matadouro já

\footnotetext{
${ }^{54}$ Código de Posturas. "Título IV - Economia e aceio dos curraes e matadouros, açougues publicos ou talhos. Artigo $\S 10^{0 "}$ In: CODIGO DE POSTURAS Leis, decretos, editais e resoluções da Intendencia municipal do Distrito Federal. Compilação feita por ordem da Prefeitura, pela repartição do Archivo Geral. (Rio de Janeiro - Papelaria e Typografia Mont'Alverne. 1894),

${ }^{55} \mathrm{An}$ agencement is a rapport of forces that makes some beings capable of making other beings capable, in a plurivocal manner, in such a way that the agencement resists being dismembered, resists clear-cut distribution. What constitutes the agent and the patient is distributed and redistributed incessantly. [...]. whose direction cannot be determined [...] Agency is the product of this agencement; there is no agency without agencement. Vinciane Despret. "From secret agents to interagency".2013. 38

${ }^{56}$ Diário do Rio de Janeiro 22/09/1832; Idem 28/12/1839.

57 Beaurepaire Rohan 1843 apud Eliara Beck Souza; Ana Maria Gadelha Albano Amora. 0 asylo da mendicidade e os planos urbanísticos do século XIX no Rio de Janeiro. 2014.

58 Verena Andreatta. Cidades quadradas, paraísos circulares: os planos urbanísticos do Rio de Janeiro no século XIX. Rio de Janeiro: Mauad X, 2006.
} 
aparecia como elemento da cidade a ser pensado nos primórdios dos projetos de reforma urbano que se desdobrariam ao longo próximas décadas.

Talvez por conta destas diferentes percepções que três anos depois, em 1846, quando o viajante inglês Thomas Ewbank relata que durante seu passeio pela orla da cidade em direção ao Morro da Glória, se depara com o prédio do matadouro de Santa Luzia, sua reação é uma só: "Como eu não tinha o menor desejo de revisitar o local, eu concluí que deveria dar uma primeira e última olhada no matadouro"59.

Se o viajante inglês preferia evitar ver o matadouro, a relação de alguns habitantes do Rio de Janeiro com aquele mesmo local era outra. Do mesmo modo que o matadouro e seu curral eram elaborados para utilizar águas das marés na limpeza, as águas da praia de Santa Luzia eram igualmente utilizadas por uma parcela da população que, incentivada pelo saber médico, tomava banho de mar em jejum e durante a madrugada ${ }^{60}$ e possivelmente também pelo fato de que a madrugada era um período alternado aos horários das matanças.

Ainda no que diz respeito às praias, foi durante a década de 1850 que os problemas do matadouro emergiram para além do abastecimento de carne verde. Algumas praias passaram a ser consideradas como imundos depósitos de fezes e lixo, ${ }^{61}$ mudança de percepção que afetaria parte dos seis mil banhistas diários que por volta dos anos de $1850^{62}$ frequentavam parte as praias da Lapa, Glória, Russel, Flamengo e a enseada de Botafogo.

Em Janeiro de 1853 quando a cidade do Rio de Janeiro já estava sob o flagelo das epidemias, é afirmado em relatório da Câmara que era impossivel continuar usando o matadouro em Santa Luzia:

Este matadouro acha-se arruinado, apesar de algumas obras ainda há pouco tempo nele feitas, e qualquer que seja o modo por que ali se procure fazer o

\footnotetext{
59 "As I had no wish to revisit the place, I concluded to take a first and last look at the Matadoura." EWBANK, Thomas. Life in Brazil; or A Journal of a visit to the Land of the cocoa and the palm. Harper \& Brothers Publisher. 1856. P. 64

60 Idem

61 Domingos Martins Guerra. "Os morros do castelo e Santo Antonio são uteis ou nocivos à saúde púbica? Durante o desmoronamento destes morros correria a cidade algum perigo?" (Rio de Janeiro Faculdade de Medicina do Rio de Janeiro, 1852) 272-273 Apud Jaime Benchimol. Pereira Passos, um Haussmann tropical, 1990. 117

62 Bruno Capilé. "Os muitos rios do Rio de Janeiro. Transformações e interações entre dinâmicas sociais e sistemas fluviais na cidade do Rio de Janeiro (1850-1889)". (Tese de doutorado , niversidade Federal do Rio de Janeiro. 2018).
} 
serviço, é de evidente verdade que por sua pequenez já não satisfaz as necessidades do dia. ${ }^{63}$

Mesmo matando-se diariamente uma média de 145 bois, e entre 200 e 230 em finais de semana e feriados, a imprevisibilidade do crescimento do sistema urbano, especialmente após o aumento populacional após 1808, é perceptível no tom em que o prédio do matadouro de Santa Luzia é descrito. Ademais, é nesta mesma década de 1850 que a separação entre pestilentos atuais e pestilentos virtuais ${ }^{64}$ (aqueles que podem vir contrair alguma doença) estava ganhando cada vez mais força. Isto se dá principalmente após os eventos epidêmicos de febre amarela em 1850 e de cólera em 1855 que colocariam em evidência a questão da salubridade pública ${ }^{65}$, demarcando-se assim uma crise de saúde pública que afetou a cidade do Rio de Janeiro entre 1850 e $1920^{66}$. Calamidades que somente nos primeiros nove anos (1851 a 1860) somaram mais de 40 epidemias registradas. ${ }^{67}$

É neste inicio dos anos 1850, época das grandes epidemias, que é consolidada a Junta de Higiene Pública, uma instituição que "era encarregada de propor e executar as medidas necessárias à preservação da saúde pública na corte e nas províncias", 68 estava atrelada a emergência de saberes neo-hipocráticos inspirados no tratado de Hipócrates "Ares, águas e lugares" e que consideravam a origem das doenças no ambiente e suas características climáticas, meteorológicas e topográficas e não mais nos indivíduos e em seus desequilíbrios de humores corporais ${ }^{69}$ que então levariam ao aparecimento, ou não, de doenças. Passa-se a falar "então de mefitismo para designar o que é malsão, fazendo referência mais particularmente aos vapores terrestres malsãos."70

\footnotetext{
63 Relatório municipal, apresentado em o dia 17 de janeiro de 1853 à câmara municipal eleita, pelo presidente da transacta, o Dr. Candido Borges Monteiro. In: Jornal do Commércio 28/01/1853.

64 Claudio Ulpiano. - "Nietzsche: A Individuação e a identidade ou A conquista da diferença. Aula de 20/08/1989". Disponível em: $<$ https://acervoclaudioulpiano.com/2016/11/18/aula-de-20081989-nietzsche-a-individuacao-e-a-identidade-ou-a-conquista-dadiferenca-2/> Acesso em 20/02/2020

${ }^{65}$ Sidney Chalhoub. "Cidade febril: cortiços e epidemias na corte imperial". (Companhia das Letras, São Paulo 1996); Elizabete Vianna Delamarque. "Junta central de higiene pública: vigilância e polícia sanitária (antecedentes e principais debates)". Dissertação de Mestrado, Fundação Oswaldo Cruz. Rio de Janeiro. 2011) Maria Luiza Marcilio. "Mortalidade e morbidade da cidade do Rio de Janeiro imperial". Revista de História, São Paulo (ago-dez/92 a jan-jul/93) 53-68

66 Sidney Chalhoub. Cidade febril., 1996

67 Maria Luiza Marcilio. Mortalidade e mordidade. 92/93

68 Jaime Benchimol, Pereira Passos, um Haussmann tropical, 1990, 114

69 Líquidos do corpo humanos, tais como o sangue, a linfa e a água.

70 CHASLES, Virginie. Saúde urbana e higienismo, o exemplo da França. Revista do Instituto de Estudos Brasileiros, Brasil, n. 64, p. 65-74, ago. 2016.P.67
} 
Apesar da crença na existência dos miasmas ser anterior a meados da década de 1850, o conceito de miasma, constituinte da teoria hipocrática e imerso nesta emergência neo-hipocrática, aprofunda-se na fundamentação de um conhecimento que ilumina e passa a explicar as ocorrências epidêmicas e higiênicas daquele Rio de Janeiro oitocentista ao considerar os miasmas - maus ares- tais como emanações e odores fétidos provenientes de matéria orgânica em putrefação no solo ou corpos d'água, como os disseminadores de doenças. $O$ que levou a modificações e aprofundamento de preocupações em relação as alterações climáticas tais como: ausência de chuvas somadas a um clima mais quente e úmido do que o habitual; a existência de pântanos e águas paradas por toda a cidade e das praias que agora exalavam odores considerados fedores e que eram resultantes de detritos domésticos em decomposição e dos corpos de espécies animais que apodreciam nas ruas.

Estas sensíveis mudanças na percepção e formas de conviver com as doenças e seu contágio, com a circulação de pessoas e em relação ao ambiente urbano invariavelmente refletiram nos matadouros quando estes deveriam ser integrados em projetos de reordenação do ambiente urbano Carioca.

Com o respaldo de toda esta mudança no saber médico científico, após sua desativação em 1854, o antigo Matadouro na praia de Santa Luzia é transformado em um albergue de mendigos abrigando inicialmente cerca de setenta pessoas. ${ }^{71}$

\footnotetext{
"Novas advertências da impressa despertaram novamente a autoridade, e de vez em quando a policia dava caça aos mendigos, e isto os refreou, mas seu número tem sido sempre crescido, ainda a mendicidade é um meio de vida para muitos indivíduos, que poderiam trabalhar, e a policia administrativa, no tempo do Sr. Siqueira, estabeleceu uma casa, ao pé do antigo matadouro, onde os mendigos vagabundos vão pernoitar., ${ }^{72}$
}

O tom moralizador e o ímpeto punitivista são claramente envolvidos por uma indignação, permitindo entrever uma nova forma de conviver com a mendicância. "Doravante, a miséria não é mais considerada numa dialética da humilhação e da glória, mas numa certa relação entre a desordem e a ordem que a encerra numa culpabilidade". ${ }^{73}$ As epidemias não haviam somente transformado a medicina do

\footnotetext{
71 Eliara Beck Souza; Ana Maria Gadelha Albano Amora . O asylo da mendicidade . 2014.

72 Carta de João Fernandes a seu compadre Manoel Mendes. Correio da tarde. Rio de Janeiro. 14-04-1856.

73 Michel Foucault, História da loucura na Idade Clássica, Coleção Estudos. Filosofia (São Paulo : Perspectiva, 2007). 67
} 
período, as tentativas de sanear a cidade e o enfoque epidemiológico ${ }^{74}$, mas também trouxeram a tona a medicina social e as tentativas de sanear a sociedade daqueles indivíduos que carregavam as pestes da saúde e do corpo orgânico,assim como as pestilências da miséria.

Devidamente desativado o matadouro de Santa Luzia, entraria em funcionamento o matadouro de São Cristóvão, de modo que as práticas de matança animal trocariam à beira do mar e as areia da praia pela lama dos mangues.

\section{CONCLUSÃo}

O primeiro matadouro público do Rio de Janeiro era um espaço de constantes interações entre mundo biofísico, humanos e espécies animais destinadas ao consumo humano e da cidade com seus habitantes.

Após funcionar por mais de 76 anos, em 1853, durante os eventos epidêmicos dos anos 1850 e com a emergência de um saber epidemiologico que contrastava a teoria miasmática, o matadouro acaba sendo desativado e depois transformado em Albergue.

Com o antigo matadouro de Santa Luzia transformado em albergue e com a abertura do matadouro de São Cristóvão, ambos passariam a funcionar como máquinas concretas de apagamento.

Enquanto o local de pernoite dos mendigos permitia afastá-los das ruas da cidade e esmaeciam estes indivíduos da percepção da população, o novo matadouro de São Cristóvão também funcionava como um modo de afastar as sensações deletérias que um matadouro de bois passava a causar em uma população que vinha crescendo, ocupando novos espaços dentro da cidade e passava a viver sob a égide de novos saberes científicos e práticas médicas.

De todo modo, e apesar das dimensões morais que possam ser elencadas, as ações humanas apresentam sempre diferentes formas de dinâmica conjunta com o

\footnotetext{
74José Ricardo de Carvalho Mesquita Ayres, Desenvolvimento histórico-epistemológico, 2009; Jaime Benchimol, Pereira Passos, um Haussmann tropical, 1990; Sidney Chalhoub, A Cidade Febril, 1996.
} 
mundo biofísico, de traçar estratégias diante da imprevisibilidade e contingências do crescimento urbano e de se portar de acordo com as disposições do mundo.

Não que a espécie humana seja ativa e o mundo biofísico junto de outras espécies animais sejam reativos as ações humanas. Se tratam de constantes interações daquilo que comumente referenciamos como da ordem do cultural com elementos do chamado mundo natural dando forma a uma cidade onde diferentes espécies interagiam e deixavam seus rastros no mar e na areia.

\section{AgRADECIMENTOS}

O autor agradece ao financiamento da CAPES e aos pareceristas do artigo que muito auxiliariam na confecção deste texto.

\section{REFERÊNCIAS}

Andreatta, Verena. Cidades quadradas, paraísos circulares: os planos urbanísticos do Rio de Janeiro no século XIX. Rio de Janeiro: Mauad X, 2006.

Ayres, José Ricardo de Carvalho Mesquita. Desenvolvimento histórico da epidemiologia e do conceito de risco. 2009.

Benchimol, Jaime. Pereira Passos, um Haussmann tropical: a renovação urbana da cidade do Rio de Janeiro no início do século XX. 1990.

Bosi, Antonio. Pádua. Dos Açougues aos Frigoríficos Uma História Social do Trabalho na Produção de Carne, 1750 a 1950. Revista de História Regional. 19(1): 83-103, 2014;

Campos, Pedro Henrique Pereira. Nos Caminhos da Acumulação: negócios e poder no abastecimento de carnes verdes para a cidade do Rio de Janeiro, 1808-35. Dissertação de mestrado - História - (UFF). Niterói, 2007;

Ewbank, Thomas. Life in Brazil; or A Journal of a visit to the Land of the cocoa and the palm. Harper \& Brothers Publisher. New York. 1856;

Capilé, Bruno. Os muitos rios do Rio de Janeiro. Transformações e interações entre dinâmicas sociais e sistemas fluviais na cidade do Rio de Janeiro (1850-1889). Rio de Janeiro, 2018. Tese (doutorado) - Universidade Federal do Rio de Janeiro, Instituto de História, Programa de Pós Graduação em História Social - 2018.

Carta de João Fernandes a seu compadre Manoel Mendes. Correio da tarde. Rio de Janeiro. 14-04-1856.

Carta do ouvidor-geral do Rio de Janeiro, Agostinho Pacheco Teles, ao rei [D. João V], 
informando a inexistência de uma provisão, que determine o aumento do salário do escrivão da Câmara daquela cidade pelo registro das cabeças de gado entregues no açougue municipal.

Disponível: <http://acervo.redememoria.bn.br/redeMemoria/handle/123456789/203041> Acesso: 26/05/2017

Codigo de Posturas Leis, decretos, editais e resoluções da Intendencia municipal do Distrito Federal. Compilação feita por ordem da Prefeitura, pela repartição do Archivo Geral. Rio de Janeiro - Papelaria e Typografia Mont'Alverne. 1894, p.6

Dean, Joanna. Animal Matters: Bovine Smallpox Vaccine at the Connaught Laboratories and University Farm. In: Adcock, Tina. Ed. Landscapes of Science. Toronto: Network in Canadian History and Environment, 2018

Daston, Lorraine, MITMAN, Gregg.; Introduction: How and Why of Thinking with Animals. In: Thinking with animals: new perspectives on anthropomorphism New York: Columbia Univ. Press, 2005.

Debret, Jean-Baptiste. Voyage pittoresque et historique au Brésil. Tome deuxième.

Delamarque, Elizabete Vianna. Junta central de higiene pública: vigilância e polícia sanitária (antecedentes e principais debates). Dissertação (Mestrado em História das Ciências e da Saúde)-Fundação Oswaldo Cruz. Rio de Janeiro. 2011;

Deleuze, Gilles. Foucault. Tradução Claudia Sant'Anna Martins; revisão da tradução Renato Ribeiro. São Paulo: Brasiliense, 2005. $5^{\circ}$ Reimpressão

Despret, Vinciane. From secret agents to interagency. History and Theory, 52: 29-44. doi:10.1111/hith.10686;

Dias, Juliana Vergueiro. O rigor da morte: a construção simbólica do "animal de açougue" na produção industrial brasileira. 2009. Dissertação (Mestrado Antropologia Social) Universidade Estadual de Campinas;

Eugenio, Alisson. Saber médico, cultura e saúde pública no brasil do século XIX. sÆculum - revista de história [22]; João Pessoa, jan./ jun. 2010.

Foucault, Michel. História da loucura na Idade Clássica. Coleção Estudos. Filosofia. São Paulo: Perspectiva, 2007.

Govindrajan, Radhika. Animal Intimacies: Interspecies Relatedness in India's Central Himalayas. 1 edition. Chicago: University of Chicago Press, 2018.

Heise, Ursula K.; Christensen, Jon; Niemann, Michelle. The Routledge companion to the environmental humanities. New York, NY: Routledge, 2016.

Kean, Hilda; Howell, Philip. The Routledge Companion to Animal-Human History. First published 2019. Routledge.

Lee, Paula Young. Meat, Modernity, and the Rise of the Slaughterhouse". University Press of New England, 2008. 
Lemke, Thomas. Biopolitik zur Einfuhrung./Biopolitics: An Advanced Introduction.Translated by Eric Frederick Trump. New York University Press. 2011.

Luccock, John. Notes on Rio de Janeiro, and the Southern parts of Brazil; taken during a residence of ten years in that country, from 1808 to 1818. London, 1820.

Maclachlan, Ian. 2007. A bloody offal nuisance: the persistence of private slaughterhouses in nineteenth-century London. Urban History / Volume 34 / Issue 02 / August 2007, pp 227 - 254;

Marcilio, Maria Luiza. Mortalidade e morbidade da cidade do Rio de Janeiro imperial. Revista de História, São Paulo, n-127-128, p. 53-68, ago-dez/92 a jan-jul/93

Mcdonald, Tracy., VANDERSOMMERS, Daniel. Zoo Studies: A New Humanities. 1. ed. McGill-Queen University Press, 2019

Mcfarland, Sarah; hediger, Ryan. Animals and agency: an interdisciplinary exploration. 2009 - Koninklijke Brill NV, Leiden, The Netherlands;

Mcneur. Catherine. Taming Manhattan: environmental battles in the antebellum city. Harvard University Press. London, England. 2014.

Mumford, Lewis. A cultura das cidades. Tradução Neil R. da Silva. Belo Horizonte: Itatiaia, 1961.p.237

A cidade na história: suas origens, transformações e perspectivas. 2.ed. São Paulo: Martins Fontes, 1982.

Niza, Samuel et. al. "Lisbon's womb: an approach to the city metabolism in the turn to the twentieth century". Regional Environmental Change (16(6):1-13 2016)

Otter, Chris. "Planet of Meat: A Biological History". Material Powers: Challenging (the) Humanities (Canberra: The Australian Academy of the Humanities, 2013)

. The vital city: public analysis, dairies and slaughterhouses in nineteenth-century Britain. 2006. Cultural geographies p. 517-537;

Relatório municipal, apresentado em o dia 17 de janeiro de 1853 à câmara municipal eleita, pelo presidente da transacta, o Dr. Candido Borges Monteiro. In: Jornal do Commércio 28/01/1853.

Rocha, L. V. E. da. Passagens e novas fronteiras dos abates: o Matadouro Municipal de Ponta Grossa e a historicidade dos espaços de matança animal centralizada. Dissertação (Mestrado em História) - Universidade Estadual de Ponta Grossa, Ponta Grossa, 2015.

Robichaud, A. Trail of Blood The Movement of San Francisco's Butchertown and the Spatial Transformation of Meat Production, 1849-1901. 2010 Stanford University Spatial History Lab.

Press, 2019. . Animal City: The Domestication of Urban America. Harvard University 
Silva, Manoel Vieira da. Reflexões sobre alguns dos meios propostos por mais conducentes para melhorar o clima da cidade do Rio. Rio de Janeiro, RJ: Impr. Régia, 1808. 27p. [1]f, $19 \mathrm{~cm}$.

Simoes, Teresa-Cristina Duarte. A saúde pública no Rio de Dom João. Caravelle. Cahiers du monde hispanique et luso-brésilien, Presses Universitaires du Mirail, 2008, pp.285-287.

Souza, Eliara Beck; Amora, Ana Maria Gadelha Albano. O asylo da mendicidade e os planos urbanísticos do século XIX no Rio de Janeiro. 2014.

Sterckx, Roel, Animal to Edible - The Ritualization of Animals in Early China In: Sterckx, Roel; Siebert, Martina; Schäfer, Dagmar. (Org). Animals through Chinese History: earliest Times to 1911. New York, NY: Cambridge University Press, 2019.

Swyngedouw, Erik. "The City as a Hybrid -- On Nature, Society and Cyborg Urbanisation", Capitalism, Nature, Socialism, (Vol. 7(1), Issue 25 March. 1996)

Tavares, Georgia. A atuação dos marchantes no Rio de Janeiro colonial. Estratégias de mercado e redes de sociabilidade no comércio de abastecimento de carne verde 17631808. 2012.

Ulpiano, Claudio. - Nietzsche: A Individuação e a identidade ou A conquista da diferença. Aula de 20/08/1989

Vialles, Noëlie. Animal to edible. Cambridge Univ. Press [u.a.] 1994. 142p;

West, Geoffrey. Scale: The Universal Laws of Growth, Innovation, Sustainability, and the Pace of Life in Organisms, Cities, Economies, and Companies. Penguin: 2017

Wirtz, Patrick H. Zoo city: Bourgeois values and scientific culture in the industrial landscape, Journal of Urban Design, 1997; 2:1, 61-82; 


\title{
The meat and the Sea: the slaughterhouse on the beach of Santa Luzia (1777-1853)
}

\begin{abstract}
With factories, farms, labs and zoos, the slaughterhouses were some of the most prominent environments regarding the mediations between humans and animals in the 19th century and that can be analyzed with the theoretical and epistemological apparatuses from the environmental history and the animal-human history. That said, we will seek to address in this article the story of the slaughterhouse on the beach of Santa Luzia, the first public slaughterhouse in the city of Rio de Janeiro, and compreheending that slaughterhouse as a place of constant interactions between the biophyscal world, the animal species meant to be edible and the city with it's inhabitants. In 1853, during the epidemics of the 1850s, the slaughterhouse was deactivated and later transformed into a hostel, so that the butchering would be moved to another place, changing the beach and the sea for the city's mangroves.
\end{abstract}

Keywords: Environmental History, Slaughterhouses, Rio de Janeiro

Recibido: $29 / 11 / 2019$

Aprobado: $18 / 02 / 2020$ 